\title{
Review on Plasma Atomizer Technology for Metal Powder
}

\author{
Ario Sunar Baskoro ${ }^{1}$, Sugeng Supriadi ${ }^{1, *}$, and Dharmanto ${ }^{1}$ \\ ${ }^{1}$ Mechanical Engineering Department, Faculty of Engineering, Universitas Indonesia, Depok, Indonesia
}

\begin{abstract}
The application of plasma process is growing field covering a wide range of activities, from welding technology, coating technology, deposition technology, manufacturing technology of metal powder, and other important engineering technology. The manufacture of metal powders can be generated from the process of gas atomization, water atomization, plasma atomization, and plasma rotating electrodes process atomization. In the process of plasma atomization provides advantages in addition to producing round powder, it is also very potential for efficient processing and recycling of used and alloy materials, thus saving fuel and essential materials. These operations will have a continuing impact on our industrial society as a whole. The industry of future metal powder manufacturers that utilize plasma atomization technology is an investment strategy that has a great opportunity to grow rapidly. A variety of plasma processes for the manufacture of metal powders will be reviewed in this paper, among others, are plasma atomization and plasma rotating electrodes process atomization. They are all potentially able to control and to produce of metal powders of spherical particles, making it very profitable on powder technology applications. The purpose of this review is to summarize and provide future research for activities in the field of metal powders by plasma atomization processes. The emphasis on plasma engineering technology future research in powder making available for exploration and research needs to be met so that these future research can be realized. Finally, the future challenges of automation from the use of plasma atomization technology for additives manufacturing, powder welding and medical manufacturing.
\end{abstract}

\section{Introduction}

Currently, metal powder technology is in high demand of the world's engineering industry because there is almost no waste of material production in the manufacturing process. The manufacture of metal powders can be generated from the process of gas atomization, water atomization, plasma atomization, and plasma rotating electrodes process atomization. Each atomization process has advantages and disadvantages, both in terms of form, shape, and complexity of the process. In the powder metallurgy applications are generally required spherical particles, because they have better properties in flowability, and density. It can be obtained from the gas atomization, plasma atomization and plasma rotating electrodes process atomization [1] are shown in Table 1.

On the other hand, the plasma arc welding has long been known as one of the technologies in the welding field [2-4]. The plasma arc has a high-density of high heat source capable of melting various metals [3].

However, the application of the plasma arc covers a wide range of activities, from welding technology, coating technology, deposition technology, metal powder making technology, and other important engineering technologies. Recently, thermal plasmas produced by DC (Direct Current) [5, 6], inductively coupled RF (Radio Frequency) [7-13] or microwave disposal [14], has been used extensively for nanopowder synthesis [15-17].

The plasma arc technology that has been developed at this time includes the use of magnetic field effects directed at arc shapes to improve the focus of plasma arc configurations, thereby reducing power consumption and increasing efficiency[18]. In addition, plasma arc was also developed in the vacuum arc melting process [19] to produce a purer metal [20]. Currently, metal powder technology is in high demand by the world's engineering industry because there is virtually no waste of material production in the manufacturing process. The method of manufacturing metal powders using the atomization process is the best choice of various ways of making metal powders, due to the consideration of the quality of powder purity and has the potential to be mass produced [21]. Looking at the observation of powder characteristics of various manufacturing processes, it can be seen that the round powder can be produced from the process of Gas Atomization, Plasma Atomization and plasma rotating electrodes process atomization [1].

Currently, the development of research on plasma atomization improvements has been used to produce round titanium powder of various sizes [22]. In addition, plasma can also be used to process irregularly shaped metal particles into spherical metal powders. The 
principle works by means of metal powder particles is injected into a plasma arc to form round droplets with rapid cooling [23]. The well-rounded powder is ideal for injection molding jobs. Application of Metal Injection Molding (MIM) because it can increase the flowability of materials [24]. In addition, the surface roughness of the MIM results can also be improved by the addition of nanopowder measuring approximately $280 \mathrm{~nm}$ [25].

A variety of plasma processes for the manufacture of metal powders will be reviewed in this paper, among others, are plasma atomization and plasma rotating electrodes process atomization. The purpose of this review is to summarize and provide opportunities for activities in the field of metal powders by plasma atomization processes. The emphasis on plasma engineering technology opportunities in powder making available for exploration and research needs to be met so that these opportunities can be realized.

\section{Plasma Technology}

\subsection{Introduction to Plasma}

Plasma contains a mixture of ions, electrons, and neutral particles. A high-pressure gas passes through an electrostatic field which has a sufficient amount of electron charge and will produce a plasma arc. The resulting electrons and gas molecules collide with each other so that it can lead to the formation of ion, atoms, and excited photons. The use of plasma arcs is mostly used for plasma spraying using different physical principles [26].

The advantages of the plasma arc technology compared to traditional technology with the principle of partial oxidation, among others are the desired temperature can be adjusted by rapid response through voltage and current parameters of the plasma source. Plasma arcs can operate under atmospheric temperatures or under vacuum, and there is no direct emission of $\mathrm{CO}_{2}$ and because of the extremely high volumetric energy density that opens the way for processing the intensification [27], lower capital costs, portability, startup and fast shutdown [28].

The plasma arc is divided into two operation modes as shown in Figure 1. Thus plasma gas passes through the cavity to the end of the anode, part of the ionized plasma gas, and then plasma jet gas develops and begins to form a plasma arc column. Heat is generated by the impact of ions from the electrical power supply, thereby emitting electrons with thermo-ionic effects, and then transferred to the mainstream by diffusion, convection, and radiation.

The plasma arc column spreading throughout the entire anode cavity, the energy affecting the thermal gasforming gas heat thermally to produce a high-speed jet [29]. The plasma arcs have very high speeds up to several hundred $\mathrm{m} . \mathrm{s}^{-1}$, which are affected by the effects of narrow nozzle diameters and gas heating resulting in thermal expansion of plasma gas [28]. a.

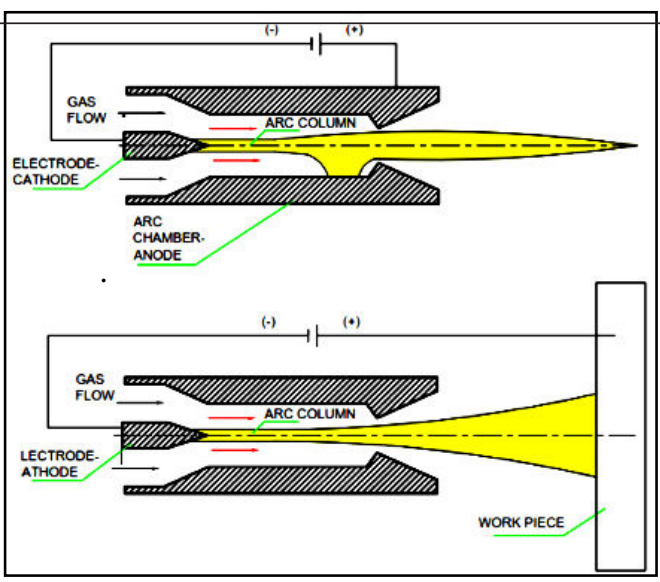

Fig. 1. Basic modes of plasma arc operation: (a). Nontransferred arc; (b). Transferred arc [30]

Plasma technology has been utilized in the steel processing industry because it has a high energy density or high specific heat. In principle, electrical energy is transformed into plasma energy which has a high temperature above $3000 \mathrm{~K}$ [31].

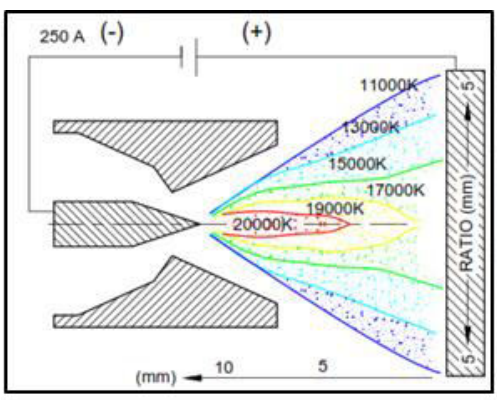

Fig.2. Distribution of temperature in the arc plasma [32]

Figure 2 shows the distribution of temperature in the arc plasma with a current of 250 Amperes. In the case of energy, this transfer is closely related to a gradient in the values of temperature, density, and composition [33].

a.

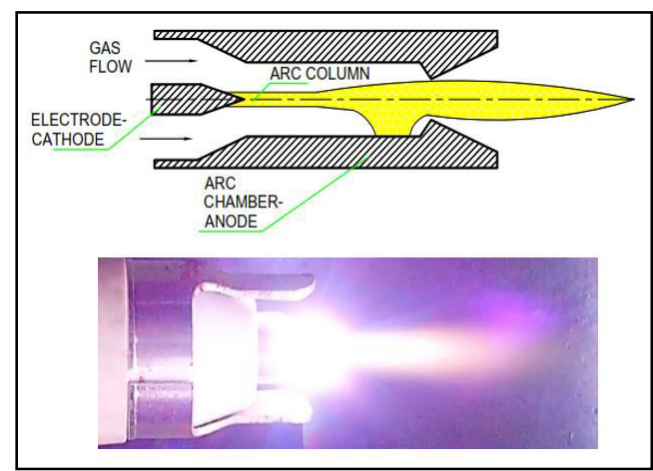

Fig. 3. (a). A simplified representation of the parallel flow arc ; (b). DC plasma arc

The plasma arcs generally have a geometry that is influenced by several parameters including the composition of the plasma gas mixture, the geometry of the electrode, the current, the voltage, the plasma nozzle design, and the flow rate of inert gas [28, 33]. The inert gas flow is also aimed at reducing the oxidation of environmental air [34]. 
The ion concentration in plasma arcs can be increased by several methods, including by the application of magnetic fields leading to arc cathodes, application of high-power microwave pulses, the application of additional currents to arc gaps and vacuum applications. A spot cathode vacuum arc is a modern concept based on the phenomenon of explosive electron emission $[35,36]$.

The emission occurs because of the high concentration of energy inside resulting in sudden warming and then the micro-explosion of the cathode surface area [37]. In addition, the result of a microburst forms a vacuum plasma arc extending into the interelectrode gap [38].

Currently, a new design of plasma cathode-ray electron sources from the principle of vacuum arc discharges under magnetic fields are designed to regulate the current electron-beam to improve the efficiency of electron beam discharges by regulating currents to control the density of plasma electron beam sources [ 38 , 39].

The current in plasma when raised from 15 A to 45 A can cause the intensity of the emission line to increase, the current density and the flow of electrons become larger, so the temperature in the plasma arc also will be higher [40].

The plasma arc is related to it is electrical conductivity and thermal. The electrical conductivity of argon gas, hydrogen gas, and nitrogen gas did not experience a significant difference in all temperatures. However, hydrogen gas and nitrogen gas have a much higher thermal conductivity compared to the thermal conductivity of argon gas, is due to the hydrogen gas and nitrogen gas including the diatom molecule so that the molecular separation into the diatoms can significantly improve the reactive thermal conductivity of the plasma gas [41] [42].

Highly high-speed plasma streams of plasma arc are generated from the dissociation process and the process of recombining the plasma gas molecules [43, 44]. Generally, argon gas is preferred because it has low ionization energy, a more stable arc pressure and a low erosion characteristic at the electrode [45].

The unavoidable weakness of DC plasma (Figure 3) is that electrode erosion that results in the electrodes in the plasma have a limited lifespan caused by very high thermal effects. (in the plasma arc nucleus can reach above 10,000-20,000 K)[27].

The plasma arc is the best choice because it has high enthalpy to increase reaction kinetics, Oxidation, high chemical reactivity, low exhaust gas, fast start-up, and small reactors. Besides, it can also be combined with a rapid cooling process that causes a relatively high volume reduction $[46,47]$.

The plasma arc in a plasma gas jet flow form that has high enthalpy. The thermal efficiency of the plasma arcs is [48]:

$$
\eta=\frac{U 1-\left(G_{\mathrm{H}_{2} \mathrm{O}} \mathrm{CP} \mathrm{H}_{2} \mathrm{O}\right.}{U T}
$$

Where, $\mathrm{U}$ is the source voltage, and I is the source current, $\mathrm{P}_{\text {total }}$ is the total power of a simple plasma arc, $\mathrm{G}_{\mathrm{H} 2 \mathrm{O}}$ is the flow rate of cooling water mass, $\mathrm{T}$ is the gradient of the temperature of the cooling water, $C_{p H^{2} O}$ is the specific heat of cooling water

The enthalpy from plasma jet, $\mathrm{h}(\mathrm{kJ} / \mathrm{kg})$, calculated from the ratio between the total inert mass flow rate and the net power used in the plasma arcs is [48] :

$$
\Delta h=\frac{\eta P_{\text {total }}}{G_{\text {ar }}+G_{\text {powder }}}
$$

Here, $G_{a r}$ is the mass flow of gas, $G_{\text {powder }}$ is the mass flow of powder $(\mathrm{kg} / \mathrm{s})$. The influence of powder on $\mathrm{h}$ has been ignored [48].

Several experiments have been conducted by previous researchers, including experiments with varying pressure, atomization gas flow rate, feed flow rate, atomization probe gap size, and droplet product size distribution. The powder product results illustrate that the size of the powder distribution increases with the decrease in plasma flows [49].

Currently, the world largest industry of spherical metal alloy powder producer for additive manufacturing (AM) at the end of 2017, has created a new plasma atomization plant. This is a profitable investment and has many benefits of plasma atomizer technology for future metal powder [50].

\subsection{Application of Plasma for Powder Technology}

\subsubsection{Plasma atomization}

Plasma technology is partially applied to the process of making metal powders. Making metal powders with plasma technology is best known as plasma atomization. Plasma atomization has been widely developed, resulting in a high purity titanium powder in various sizes of powder grains. Atomization of plasma capable of producing various sizes of titanium powder from very fine $(-25 \mu \mathrm{m})$ to rough $(+125 \mu \mathrm{m})$ [22].

Round-shaped metal powders have the benefit of having the properties of good flowability and capable of producing high density. In powder manufacturing processes, in the case of good flowability powders means requiring fewer additives than low flow powders. Whereas in case of high density means that the powder, if used in the sintering process such as hot isostatic pressure (HIPing) at the densification stage, will occur minimally [22].

Figure 4 shows a plasma atomization process scheme using a three plasma arc, with titanium wire as a material feed. The plasma arc is utilized as a highenthalpy heat source which will melt and spray molten titanium wire, resulting in a titanium powder that has a very high purity round shape [22]. 


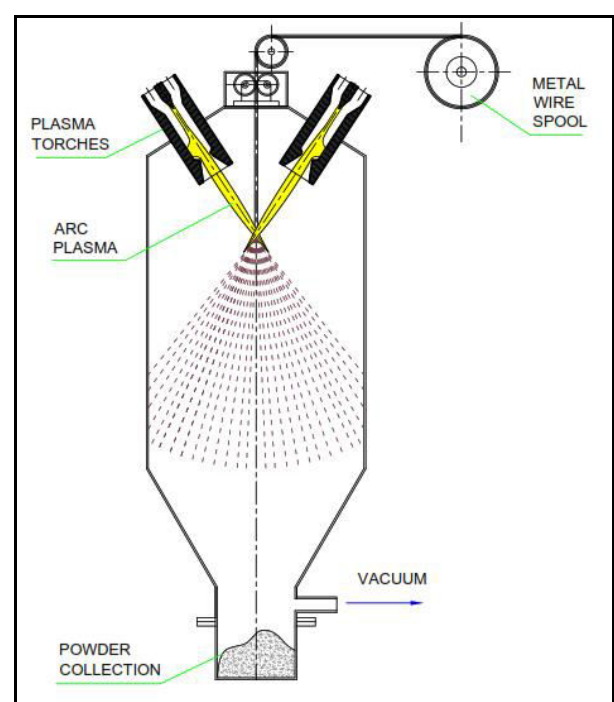

Fig. 4. Schematic representation of the plasma atomization process for the production of Ti powders [51]

\subsubsection{Plasma Rotating Electrode Process Atomization}

The plasma technology for other metal atomization applications is plasma rotating electrode process atomization. Where the rod-shaped feed material is rotated at a high rotation when the argon or nitrogen plasma arc melts the tip of the rod so that the molten metal is thrown into a grain of metal due to the high centrifugal force of the rotation of the rod. As shown in the schematic in Figure 5 [52].

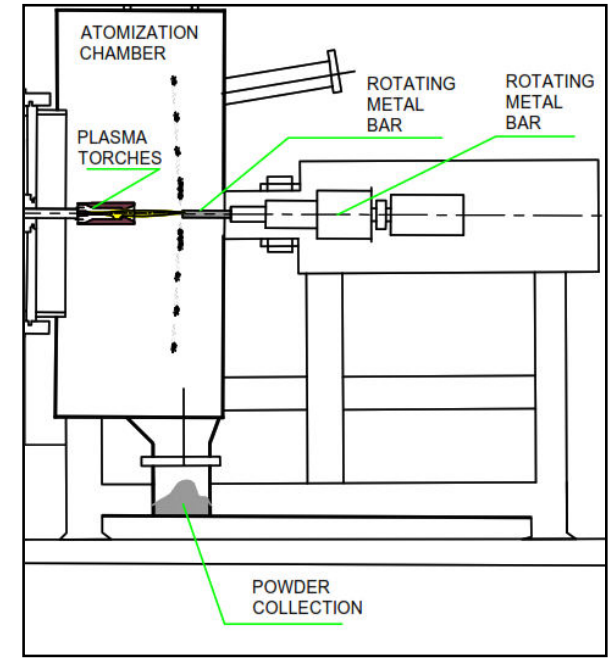

Fig. 5. Schematic set-up of the Plasma Rotating Electrode Process Atomization [52]

Various experimental conditions have been conducted to examine the droplets of metal powder thrown from the spinning metal rod as the centrifugal force has overcome the force of the melt surface stress of the metal rod. The surface tension of the metal surface of the experimental results is set as follows [45]:

$$
d_{p}=\frac{\sqrt[60]{\frac{s \sigma_{s}}{D_{a \cdot \rho_{m}}}}}{\pi n}
$$

Where, $d_{p}$ is diameter of particle $(\mathrm{m}) ; \sigma_{s}$ is molten metal surface tension $(\mathrm{N} / \mathrm{m}) ; D_{a}$ is the metal electrode diameter $(\mathrm{m}) ; \rho_{m}$ is molten metal density $\left(\mathrm{kg} / \mathrm{m}^{3}\right) ; n$ is metal electrode rotation ( $\mathrm{rpm})$

In the experiment, the material used is austenitic steel with variations of 5000 RPM rotation up to 15000 RPM, the powder yield contains nitrogen mass from 0.48 $\%$ to $0.96 \%$. The result of the metal powder is still to be processed again by the process of the sieve to the next gradation so that collected powder with a uniform grain size [52].

\subsubsection{Plasma Centrifugal Atomization}

Plasma technology for other metal powder applications is Plasma Centrifugal Atomization is shown in Figure 6. The Centrifugal Atomization plasma application is not only a melting process of the feed material but uses a rotating container to produce a centrifugal force which will improve the more rounded powder form in the crystallization stage

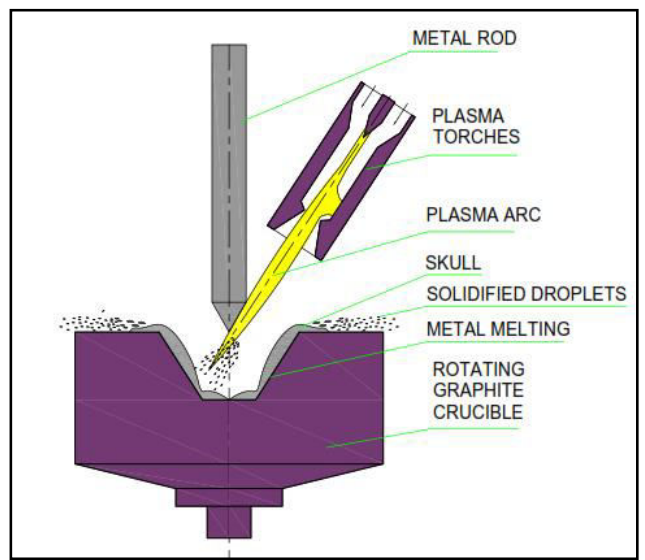

Fig.6. Schematic of the plasma centrifugal atomization design [53].

Experiments have been performed to calculate numerical results, and the initial analysis results of kinetic properties on the rotary container accommodates molten metal droplets. The calculation of the total kinetic energy approach of molten metal granules released from the rotary container surface is as follows [53]:

$$
\mathrm{E}=\frac{\left(4 \rho \pi r^{3} / 3\right) w^{2}}{2}+\frac{j \omega^{2}}{2}
$$


Where, $\mathrm{w}$ is the speed of the container rotational $(\mathrm{m} / \mathrm{sec}) ; \mathrm{J}$ is the inertia moment of the molten metal drop $\left(\mathrm{kg} \cdot \mathrm{m}^{2}\right) ; \omega$ is the speed of angular rotation of the molten metal drop (rad); $r$ is the radius of the molten metal drop $(\mathrm{m})$, and $\rho$ is the molten metal density $\left(\mathrm{kg} / \mathrm{m}^{3}\right)$.

The melt metal separation conditions from the melt surface of the feed material are primarily determined by its motion kinetic energy. The separation conditions of the grains of the radius $r$ from the melting surface are as follows [53]:

$$
2 \pi r \sigma \leq \frac{\left(4 \rho \pi r^{3} / 3\right) w^{2}}{2 R},
$$

Where, $\mathrm{R}$ is the edge radius of the melt on the rotary container $(\mathrm{m})$, and $\sigma$ is the melt surface tension $(\mathrm{N} / \mathrm{m})$.

When separating from the surface of molten metal, the granular radius can be estimated as follows [53]:

$$
r_{c r}=\frac{16.55}{n} \sqrt{\frac{\sigma}{R \rho .} \cdot m}
$$

Where $\mathrm{n}$ is the rotating frequency of the crucible with the melted metal $\left(\min ^{-1}\right)$. The radius of crucible about $3 \cdot 10^{-2} \mathrm{~m}$ and frequency of rotating about $10^{4} \mathrm{~min}^{-}$ ${ }^{1}$, The melt density about $7.8 \cdot 10^{3} \mathrm{~kg} / \mathrm{m}^{3}$ and the surface tension approximately $1.85 \mathrm{~N} / \mathrm{m}$ [53].

If the calculation is done with this formula on titanium metal alloy material with the same conditions of the actual experiment at surface tension $1.33 \mathrm{~N} / \mathrm{m}$ and density $4.50 .103 \mathrm{~kg} / \mathrm{m}^{3}$, resulting in a granules radius formed approximately equal to $160 \mu \mathrm{m}$. From the results of these calculations when compared with the results of actual experiments that produce $150 \mu \mathrm{m}$ granules in the same conditions more or less have a difference of $6 \%$ difference [53].

\begin{tabular}{|c|c|c|c|c|c|}
\hline $\begin{array}{c}\text { Manufacturing } \\
\text { Process }\end{array}$ & Material & $\begin{array}{c}\text { Particle Size } \\
\text { Range } \\
\end{array}$ & Advantages & Disadvantages & References \\
\hline $\begin{array}{c}\text { Water } \\
\text { Atomization }\end{array}$ & AISI316L & $44-106 \mu \mathrm{m}$ & $\begin{array}{l}\text { High production rates, large } \\
\text { particle size range, ingredients } \\
\text { in ingot form }\end{array}$ & $\begin{array}{l}\text { There is an additional } \\
\text { process of removing water, } \\
\text { irregular particle shape, wide } \\
\text { particle size distribution }\end{array}$ & [54] \\
\hline $\begin{array}{c}\text { Gas } \\
\text { Atomization }\end{array}$ & Ti Alloy & $0-250 \mu \mathrm{m}$ & $\begin{array}{l}\text { Can be used for various types of } \\
\text { alloy metals that have reactive } \\
\text { properties in ingots, large } \\
\text { particle size range, spherical } \\
\text { particles }\end{array}$ & $\begin{array}{l}\text { Wide particle size } \\
\text { distribution }\end{array}$ & [55] \\
\hline $\begin{array}{c}\text { Plasma } \\
\text { Atomization }\end{array}$ & Ti Alloy & $25-125 \mu \mathrm{m}$ & The particles are more spherical & $\begin{array}{l}\text { The feedstock must be } \\
\text { in the form of wire or } \\
\text { powder, costly }\end{array}$ & [22] \\
\hline $\begin{array}{l}\text { Plasma Rotating } \\
\text { Electrode } \\
\text { Process } \\
\end{array}$ & Tungsten & $160-500 \mu \mathrm{m}$ & $\begin{array}{l}\text { High purity, more spherical } \\
\text { particles }\end{array}$ & $\begin{array}{l}\text { Low productivity, } \\
\text { expensive cost }\end{array}$ & {$[52,56]$} \\
\hline $\begin{array}{c}\text { Plasma- } \\
\text { Centrifugal } \\
\text { Atomization }\end{array}$ & $\begin{array}{l}45 \text { Steel, } \\
\text { HSS, Ti } \\
\text { Alloy }\end{array}$ & $0-385 \mu \mathrm{m}$ & $\begin{array}{l}\text { Spherical particles, produced } \\
\text { easily }\end{array}$ & $\begin{array}{l}\text { The fractional } \\
\text { composition on the } \\
\text { distribution of particle } \\
\text { size is quite wide }\end{array}$ & [53] \\
\hline $\begin{array}{l}\text { Centrifugal } \\
\text { Atomization }\end{array}$ & $\begin{array}{l}\text { Magnesiu } \\
\text { m alloy }\end{array}$ & $50-800 \mu \mathrm{m}$ & $\begin{array}{l}\text { Large particle size range, } \\
\text { distribution of particle size is } \\
\text { narrow }\end{array}$ & $\begin{array}{l}\text { Difficulty in making the } \\
\text { powder with good } \\
\text { quality. }\end{array}$ & [57] \\
\hline
\end{tabular}

Table 1. Advantages and disadvantages on the process of powder manufacturing

\subsection{Powder Standart for Medical Manufacturing}

Based on previous studies that powder manufacturing results have ease of fabrication, good mechanical properties, and economic advantages applied to very complex shapes. Therefore, it is indispensable in medical manufacturing. Although there are limits to lower corrosion resistance because high areas can affect corrosion reactions. Various studies have been conducted to optimize corrosion resistance, one of them by adding alloying elements of metal.[58]
The result of the addition of alloy elements using powder among them is found in AISI 316L, Ti-6Al-4V alloy, Co-Cr-Mo alloy, as a medical manufacturing material. Materials such medical manufacturing as an orthopedic metallic implant material [59]. Standard Characteristics of medical manufacturing are shown in Table 2. 
Table 2. Characteristics of metallic powder standart for medical manufacturing [59]

\begin{tabular}{|l|l|l|}
\hline Material & Designation & Elements (wt\%) \\
\hline $\begin{array}{l}\text { Stainless } \\
\text { steels }\end{array}$ & ASTM F-138 & $\mathrm{Cr}(17.0-20.0)$, \\
& (AISI 316 L) & $\begin{array}{l}\mathrm{Ni}(12.0-14.0), \\
\mathrm{Mo}(2.0-4.0),\end{array}$ \\
& & $\mathrm{Fe}($ balance.), \\
\hline $\begin{array}{l}\text { Cobalt- } \\
\text { alloys }\end{array}$ & ASTM F-1537 & $\mathrm{Cr}(19.0-30.0)$ \\
& ASTM F-799 & $\mathrm{Mo}(0-10.0), \quad \mathrm{Ni}(0-$ \\
& & $37.0, \mathrm{Co}($ balance $)$, \\
\hline $\begin{array}{l}\text { Ti and Ti- } \\
\text { alloys }\end{array}$ & ASTM F-1295 & $\mathrm{V}(4), \mathrm{Al}(6), \mathrm{Nb}(7)$, \\
& ASTM F-136 & \\
\hline
\end{tabular}

\section{Future Researches}

Based on several atomization processes of plasma technology that have been studied and published in the description above, the next research is promising, among others, research to overcome the erosion that occurs in DC plasma arc electrode [60] to keep the gap distance between the cathode and anode is always stable in the condition the same so that the plasma arc temperature can always be kept stable. In the end, it can produce more uniform powder grains. The preliminary design of future research that we are working on has been shown in Figure 7.

The working principle of gear 1 will continuously rotate the gear 2 with the screw so that the cathode electrode will decrease according to the amount of erosion occurring at the electrode based on previous experiments so that the gap between the cathode electrode and anode electrode can always be stable.

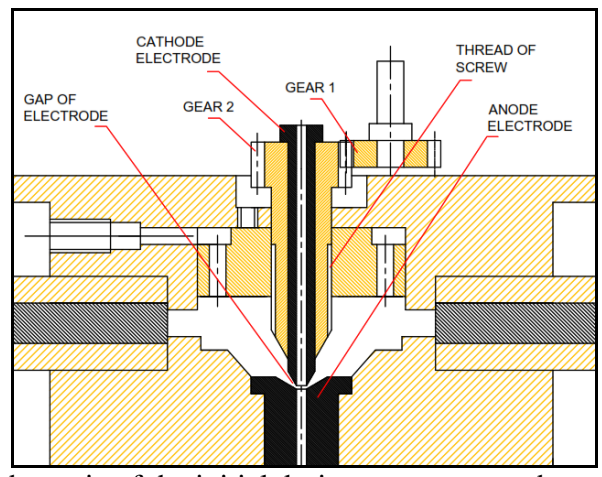

Fig. 7. Schematic of the initial design to overcome the erosion of the plasma electrode

Development of plasma atomization based on several atomization processes of plasma technology, which has been studied and published in the above description, subsequent research is quite promising, among others, research for the application of controls with machine vision [61] that is applied to the plasma atomization. The preliminary design of future research that we are working on has been shown in Figure 8. The atomization angle of the plasma arc is visualized by the camera to characterize the plasma arc, with card data acquisition (DAQ) [62] is used to control the atomization process of plasma.

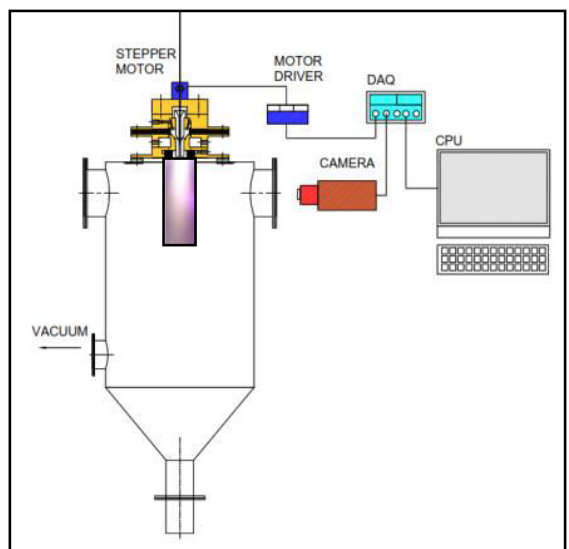

Fig. 8. Schematic diagrams of machine vision of plasma atomization

Machine vision on atomization by modifying, using a microcontroller to adjust the input speed of the material for the purpose of adjusting the results of the plasma arc in atomization. The size of the small particles is estimated based on the data the arc pattern obtained from the machine vision base on currents, metal feed rate, and gas flow rate. It used to get a series of data to be performed as a preliminary experiment to train and to build a system of neural networks $[61,62]$.

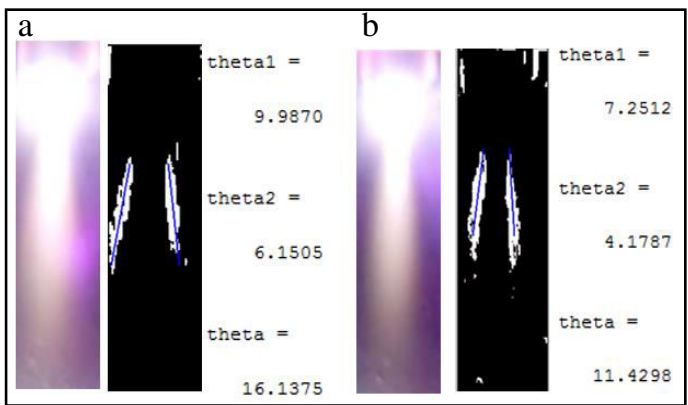

Fig. 9. Samples of Detection Edge Mask Sobel and BW Threshold 0,2 with Matlab; (a). The effect of the gas pressure of $80 \mathrm{psi}$; (b). The effect of the gas pressure of $70 \mathrm{psi}$

Figure 9 shows the plasma arc angle values of (a) $16.1375^{\circ}$ and (b) $11.4298^{\circ}$, with the gas pressure of $80 \mathrm{psi}$ and 70 psi respectively. Due to the rapid spread of the air jet is generated from the higher airflow resulting in a wider spray angle [63]. The phenomenon that occurs can be seen with the image processing using Detection Edge Mask Sobel Method with threshold 0,2 shows that function on plasma atomization to keep the atomization results have a specific particle size allows using machine vision. If the plasma arc atomic angle is wider, it is possible to produce a smaller powder size.

\section{Conclusion}

The process of plasma atomization for the manufacture of metal powders of spherical particles can be produced from plasma atomization, plasma centrifugal atomization, and Plasma Rotating Electrode Process. 
The phenomenon of plasma arc angle values that occur can be identified by image processing using the Detection Edge Mask Sobel Method with threshold 0,2. It is possible to be used as a sensor input on the machine vision controller to keep the atomization results having a specific particle size.

They all potentially can be developed equipped with a machine vision system to control and to produce of metal powders of spherical particles, making it particularly advantageous in the application of powder technology for additive manufacturing, powder welding and medical manufacturing.

This research work has been supported by the Ministry of Technology Research and Higher Education of The Republic of Indonesia with the scheme of Excellent Applied Research in Higher Education in 2018 (PTUPT from Ristek DIKTI in 2018)

\section{References}

1. J. Dawes, R. Bowerman, and R. Trepleton, "Introduction to the additive manufacturing powder metallurgy supply chain," Johnson Matthey Technology Review, vol. 59, pp. 243-256, (2015)

2. B. $\mathrm{Xu}$, "Theory and technology of equipment remanufacturing engineering," National Defense Industrial Press, Beijing, (2007)

3. Y.-H. Lü, Y.-X. Liu, F.-J. Xu, and B.-S. Xu, "Plasma transferred arc forming technology for remanufacture," Advances in Manufacturing, vol. 1, pp. 187-190, (2013)

4. C. Doumanidis, "Three-dimensional welding update rapid prototyping report," in Am Soc Mech Eng, , pp. 41-45. (1999)

5. C.-Y. Tsai, H.-C. Hsi, H. Bai, K.-S. Fan, and C. Chen, "TiO 2- $\mathrm{x}$ nanoparticles synthesized using $\mathrm{He} / \mathrm{Ar}$ thermal plasma and their effectiveness on lowconcentration mercury vapor removal," Journal of Nanoparticle Research, vol. 13, pp. 4739-4748, (2011)

6. S.-M. Oh and D.-W. Park, "Production of ultrafine titanium dioxide by DC plasma jet," Thin Solid Films, vol. 386, pp. 233-238, (2001)

7. Y.-L. $\mathrm{Li}$ and T. Ishigaki, "Controlled one-step synthesis of nanocrystalline anatase and rutile $\mathrm{TiO} 2$ powders by in-flight thermal plasma oxidation," The Journal of Physical Chemistry B, vol. 108, pp. 1553615542, (2004)

8. Y. Tanaka, H. Sakai, T. Tsuke, Y. Uesugi, Y. Sakai, and K. Nakamura, "Influence of coil current modulation on $\mathrm{TiO} 2$ nanoparticle synthesis using pulse-modulated induction thermal plasmas," Thin Solid Films, vol. 519, pp. 7100-7105, 2011.

9. H. Peng, B. Liuyang, Y. Lingjie, L. Jinlin, Y. Fangli, and C. Yunfa, "Shape-controlled synthesis of $\mathrm{ZnS}$ nanostructures: a simple and rapid method for onedimensional materials by plasma," Nanoscale research letters, vol. 4, p. 1047, 2009.

10. T. Ishigaki and J.-G. Li, "Synthesis of functional TiO2based nanoparticles in radio frequency induction thermal plasma," Pure and Applied Chemistry, vol. 80, pp. 1971-1979, 2008.

11. J. Li, M. Ikeda, R. Ye, Y. Moriyoshi, and T. Ishigaki, "Control of particle size and phase formation of $\mathrm{TiO} 2$ nanoparticles synthesized in RF induction plasma," Journal of Physics D: Applied Physics, vol. 40, p. 2348, 2007.

12. S.-M. Oh and T. Ishigaki, "Preparation of pure rutile and anatase $\mathrm{TiO} 2$ nanopowders using RF thermal plasma," Thin Solid Films, vol. 457, pp. 186-191, 2004.

13. J. Li, R. Büchel, and M. Isobe, "Mori T and Ishigaki T," J. Phys. Chem. C, vol. 2009, p. 113, 2009.

14. Y. C. Hong and H. S. Uhm, "Production of nanocrystalline $\mathrm{TiO} 2$ powder by a microwave plasmatorch and its characterization," Japanese Journal of Applied Physics, vol. 46, p. 6027, 2007.

15. J.-H. Seo and B.-G. Hong, "Thermal plasma synthesis of nano-sized powders," Nuclear engineering and technology, vol. 44, pp. 9-20, 2012.

16. S. X. Liu, J. L. Liu, X. S. Li, X. Zhu, and A. M. Zhu, "Gliding arc plasma synthesis of visible-light active C-doped titania photocatalysts," Plasma Processes and Polymers, vol. 12, pp. 422-430, 2015.

17. Dharmanto, S. Hendi and D. Sebayang, "The simple fabrication of nanorods mass production for the dyesensitized solar cell," in MATEC Web of Conferences, 2017, p. 03006.

18. A. S. Baskoro, A. Fauzian, H. Basalamah, G. Kiswanto, and W. Winarto, "Improving weld penetration by employing of magnetic poles' configurations to an autogenous tungsten inert gas (TIG) welding," The International Journal of Advanced Manufacturing Technology, vol. 99, pp. 1603-1613, 2018.

19. P. Chapelle, H. El Mir, J. Bellot, A. Jardy, D. Ablitzer, and D. Lasalmonie, "Modelling of the arc plasma behaviour in the VAR process," Journal of materials science, vol. 39, pp. 7145-7152, 2004.

20. D. Kostrin, A. Lisenkov, and N. Potrakhov, "Formation of Biomedical Coatings with Complex Compositions Using Vacuum Arc Plasma," Biomedical Engineering, vol. 51, pp. 262-266, (2017)

21. A. L. H.A. Kuhn, "Powder Metallurgy Processing. New Techniques and Analyses," Academic Press, 1978.

22. A. Alagheband and C. Brown, "Plasma Atomization goes commercial," Metal Powder Report, vol. 53, pp. 26-28, 1998/11/01/ 1998.

23. H. Zhu, H. Tong, F. Yang, and C. Cheng, "Plasmaassisted preparation and characterization of spherical stainless steel powders," Journal of Materials Processing Technology, vol. 252, pp. 559-566, 2018.

24. M. Boulos, "Plasma power can make better powders," Metal Powder Report, vol. 59, pp. 16-21, 2004.

25. S. Supriadi, E. Baek, C. Choi, and B. Lee, "Binder system for STS 316 nanopowder feedstocks in micrometal injection molding," Journal of Materials Processing Technology, vol. 187, pp. 270-273, 2007. 
26. M. F. Zhukov and I. Zasypkin, Thermal plasma torches: design, characteristics, application: Cambridge Int Science Publishing, 2007.

27. L. Fulcheri, F. Fabry, S. Takali, and V. Rohani, "Three-phase AC arc plasma systems: a review," Plasma Chemistry and Plasma Processing, vol. 35, pp. 565-585, 2015.

28. S. Mohsenian, M. S. Esmaili, B. Shokri, and M. Ghorbanalilu, "Physical characteristics of twin DC thermal plasma torch applied to polymer waste treatment," Journal of Electrostatics, vol. 76, pp. 231237, 2015.

29. V. Rat, F. Mavier, and J. Coudert, "Electric arc fluctuations in dc plasma spray torch," Plasma Chemistry and Plasma Processing, vol. 37, pp. 549580, 2017.

30. K. Nishiguchi, "Plasma arc welding and cutting," in Advanced Joining Technologies, ed: Springer, 1990, pp. 36-47.

31. G. Mauer, R. Vaßen, and D. Stöver, "Plasma and particle temperature measurements in thermal spray: approaches and applications," Journal of thermal spray technology, vol. 20, pp. 391-406, 2011.

32. S. Samal, "Thermal plasma technology: The prospective future in material processing," Journal of cleaner production, vol. 142, pp. 3131-3150, 2017.

33. E. Nogues, M. Vardelle, P. Fauchais, and P. Granger, "Arc voltage fluctuations: Comparison between two plasma torch types," Surface and Coatings Technology, vol. 202, pp. 4387-4393, 2008.

34. I. Gulyaev, A. Dolmatov, M. Y. Kharlamov, P. Y. Gulyaev, V. Jordan, I. Krivtsun, et al., "Arc-plasma wire spraying: an optical study of process phenomenology," Journal of Thermal Spray Technology, vol. 24, pp. 1566-1573, (2015)

35. G. Mesyats and E. Oks, "Charge distribution of ions in low-current vacuum-arc plasma," Technical Physics Letters, vol. 39, pp. 687-689, (2013)

36. G. Mesyats, S. Bugayev, and D. Proskurovskiy, "Explosive Emission of Electrons from Metal Tips," Uspekhi fizikicheskikh nauk, vol. 104, p. 673, 1971.

37. G. Mesyats, "Explosive Electron Emission (Fizmatlit, Moscow, 2011)," Google Scholar.

38. S. Gao, S. Chen, K. Chen, Z. Ji, and J. Chen, "A long pulse width and high extraction rate arc plasma electron beam source," Instruments and Experimental Techniques, vol. 60, pp. 705-709, 2017.

39. A. Bugaev, V. Gushenets, A. Nikolaev, E. Oks, K Savkin, V. Frolova, et al., "Generation of High Charge State Metal Ions in an Arc Plasma," Russian Physics Journal, vol. 60, pp. 1392-1399, 2017.

40. Z. F. Ghatass, G. D. Roston, and M. M. Mohamed, "Three-phase plasma arc atomic-emission spectrometric analysis of environmental samples using an ultrasonic nebulizer," Analytical and bioanalytical chemistry, vol. 376, pp. 549-553, 2003.

41. C. Xi, "Heat transfer and fluid flow under thermal 56. plasma conditions," Beijing: Science Press, vol. 429, p. 457,1993
42. L. An and Y. Gao, "Electric Characteristics of Plasma Arc Produced by Bi-Anode Torch," Journal of thermal spray technology, vol. 19, pp. 459-464, 2010.

43. G. Miloshevsky, G. Romanov, V. Tolkach, and I. Y. Smurov, "Simulation of the Dynamics of Two-Phase Plasma Jet in the Atmosphere," in Proceedings of III International Conference on Plasma Physics and Plasma Technology, 2000, pp. 18-22.

44. R. Huang, H. Fukanuma, Y. Uesugi, and Y. Tanaka, "Simulation of arc root fluctuation in a DC nontransferred plasma torch with three dimensional modeling," Journal of thermal spray technology, vol. 21, pp. 636-643, 2012.

45. T. Mohanty, B. Tripathi, T. Mahata, and P. Sinha, "Arc plasma assisted rotating electrode process for preparation of metal pebbles," in Discharges and Electrical Insulation in Vacuum (ISDEIV), 2014 International Symposium on, 2014, pp. 741-744.

46. S. Safa and G. Soucy, "Liquid and solution treatment by thermal plasma: a review," International journal of environmental science and technology, vol. 11, pp. 1165-1188, 2014.

47. A. Murphy, "Plasma destruction of gaseous and liquid wastes," Annals of the New York Academy of Sciences, vol. 891, pp. 106-123, 1999.

48. F. R. Caliari, F. S. Miranda, D. A. P. Reis, G. P. Filho, L. I. Charakhovski, and A. Essiptchouk, "Plasma torch for supersonic plasma spray at atmospheric pressure," Journal of Materials Processing Technology, vol. 237, pp. 351-360, 2016/11/01/ (2016)

49. L. Jia and F. Gitzhofer, "Nano-particle sizing in a thermal plasma synthesis reactor," Plasma Chemistry and Plasma Processing, vol. 29, p. 497, 2009.

50. J. Capus, "AP\&C opens second plasma atomized powder plant," Metal Powder Report, vol. 72, pp. 382383, 2017.

51. Grenier, "Plasma Atomization gives unique spherical powders," Metal Powder Report, vol. 52, pp. 34-37, 1997/11/01/ 1997.

52. E. Wosch, A. Prikhodovski, S. Feldhaus, and T. E. Gammal, "Investigations on the rapid solidification of steel droplets in the plasma-rotating-electrode-process," steel research international, vol. 68, pp. 239-246, 1997.

53. S. Bogdanov, "Prospects of Production of Granular Composite Materials by Method of the PlasmaCentrifugal Atomization," Metallurgist, pp. 1-8, 2018.

54. M. J. Tobar, J. M. Amado, J. Montero, and A. Yáñez, "A Study on the Effects of the Use of Gas or Water Atomized AISI 316L Steel Powder on the Corrosion Resistance of Laser Deposited Material," Physics Procedia, vol. 83, pp. 606-612, 2016/01/01/ 2016.

55. G. Chen, P. Tan, S. Y. Zhao, W. W. He, and H. P. Tang, "Spherical Ti-6Al-4V powders produced by gas atomization," Key Engineering Materials, vol. 704, 2016 .

V. Korzhyk, L. Kulak, V. Shevchenko, V. Kvasnitskiy, N. Kuzmenko, X. Liu, et al., "New Equipment for Production of Super Hard Spherical Tungsten Carbide and other High-Melting Compounds Using the Method 
of Plasma Atomization of Rotating Billet," in Materials Science Forum, 2017, pp. 1485-1497.

57. C. Labrecque, R. Angers, R. Tremblay, and D. Dube, "Inverted disk centrifugal atomization of AZ91 magnesium alloy," Canadian metallurgical quarterly, vol. 36, pp. 169-175, 1997.

58. M. M. Dewidar, H.-C. Yoon, and J. K. Lim, "Mechanical properties of metals for biomedical applications using powder metallurgy process: a review," Metals and Materials International, vol. 12, p. 193, 2006.

59. M. Long and H. Rack, "Titanium alloys in total joint replacement a materials science perspective," Biomaterials, vol. 19, pp. 1621-1639, 1998.

60. R. Knight, R. Smith, and D. Apelian, "Application of plasma arc melting technology to processing of reactive metals," International materials reviews, vol. 36, pp. 221-252, 1991.

61. A. S. Baskoro, R. Tandian, A. Edyanto, and A. S. Saragih, "Automatic Tungsten Inert Gas (TIG) welding using machine vision and neural network on material SS304," in Advanced Computer Science and Information Systems (ICACSIS), 2016 International Conference on, 2016, pp. 427-432.

62. D. Ju, X. Sun, X. Jia, Z. Huang, X. Qiao, D. Han, et al., "Experimental investigation of the atomization behavior of ethanol and kerosene in acoustic fields," Fuel, vol. 202, pp. 613-619, 2017/08/15/ (2017)

63. Y. Xia, L. Khezzar, M. Alshehhi, and Y. Hardalupas, "Droplet size and velocity characteristics of water-air impinging jet atomizer," International Journal of Multiphase Flow, vol. 94, pp. 31-43, (2017) 